\title{
Mosaicism for a pathogenic $M F N 2$ mutation causes minimal clinical features of CMT2A in the parent of a severely affected child
}

\author{
Katherine Schon ${ }^{1}$ (D) - Olivera Spasic-Boskovic ${ }^{1} \cdot$ Kim Brugger $^{1} \cdot$ Tracey D. Graves $^{2}$. \\ Stephen Abbs ${ }^{1} \cdot$ Soo-Mi Park ${ }^{1}$ - Gautam Ambegaonkar ${ }^{3}$. Ruth Armstrong ${ }^{1}$
}

Received: 14 October 2016 / Accepted: 7 December 2016 /Published online: 6 January 2017

(C) The Author(s) 2017. This article is published with open access at Springerlink.com

\begin{abstract}
Charcot-Marie-Tooth disease (CMT) refers to a genetically heterogeneous group of disorders which cause a peripheral motor and sensory neuropathy. The overall prevalence is 1 in 2500 individuals. Mutations in the MFN2 gene are the commonest cause for the axonal (CMT2) type. We describe a Caucasian 5-year old girl affected by CMT2A since the age of 2 years. She presented with unsteady gait, inturning of the feet and progressive foot deformities. Nerve conduction studies suggested an axonal neuropathy and molecular testing identified a previously reported pathogenic variant c.1090C > T, p.(Arg364Trp) in the MFN2 gene. This variant was also detected in a mosaic state in blood and saliva by Sanger sequencing in her subjectively healthy father. Next generation sequencing showed that the level of mosaicism was $21 \%$ in blood and $24 \%$ in saliva. A high recurrence risk was given because the father had proven somatic mosaicism and an affected child implying gonadal mosaicism. The parents were referred for pre-implantation genetic diagnosis. To the best of our knowledge, this is the first reported case of somatic mosaicism for MFN2. This study has important implications for genetic counselling in families with CMT2A.
\end{abstract}

Keywords MFN2 $\cdot$ CMT2A $\cdot$ Mosaicism ·

Charcot-Marie-tooth disease

Katherine Schon

Katherine.schon@addenbrookes.nhs.uk

1 East Anglian Medical Genetics Service, Cambridge University Hospitals NHS Foundation Trust, Cambridge CB2 0QQ, UK

2 Department of Neurology, Hinchingbrooke Hospital, Hinchingbrooke Park, Huntingdon PE29 6NT, UK

3 Department of Paediatric Neurology, Cambridge University Hospitals NHS Foundation Trust, Cambridge CB2 0QQ, UK

\section{Introduction}

Charcot-Marie-Tooth (CMT) disease refers to a heterogeneous group of hereditary disorders which cause a peripheral motor and sensory neuropathy. The overall prevalence is approximately 1 in 2500 [1]. They are also genetically heterogeneous with over 60 reported genes [2]. Autosomal dominant, autosomal recessive and X-linked inheritance have been described. CMT can also be classified on the basis of nerve conduction velocity into demyelinating (CMT1) and axonal (CMT2) types.

Charcot-Marie-Tooth disease type $2 \mathrm{~A}$ is caused by mutations in the MFN2 (mitofusin 2) gene (OMIM 608507). Autosomal dominant inheritance or de novo dominant mutations are reported in most families [3, 4]. Autosomal recessive inheritance or semi-dominant inheritance has also been reported, mostly with a more severe phenotype [5, 6]. CMT2A caused by heterozygous mutations in MFN2 has a variable phenotype with an early onset form with age at onset $<10$ years (mean age 3.5 years) and a late onset form with age at onset $>=10$ years (mean age 20.5 years) [3]. The early onset form is more common and usually has a more severe phenotype [3]. CMT2A is characterised by earlier and more severe involvement of the lower extremities, more severe motor than sensory involvement and normal or slightly decreased nerve conduction velocities. Some patients have additional features of optic atrophy and/or spinal cord abnormalities [4].

Mosaicism occurs when an individual who has developed from a single fertilised egg has two or more cell lines which are discordant for a genetic feature [7]. This could be a chromosomal abnormality, for example in mosaic Trisomy 21, or it could be a sequence variant. The occurrence of families with more than one affected child for an apparently de novo dominant or X-linked condition (i.e. 
where the mutation was not detected on testing parental samples) can be explained by gonadal (or germline) mosaicism. Individuals may have gonadal mosaicism only, or may have somatic and gonadal mosaicism. Somatic mosaicism is being increasingly detected as a result of next generation sequencing [8].

\section{Materials and Methods}

The family was ascertained through referral to the East Anglian Medical Genetics Service. Informed consent for publication was obtained. The proband and her father were assessed by the neurologists (GA and TDG). Electrophysiology studies (electromyography and nerve conduction studies) were performed in the proband. A peripheral blood DNA sample from the proband was tested for copy number changes on chromosome 17 using the Agilent ISCA $8 \times 60 \mathrm{~K}$ v2 array and CytoGenomics software, Edition 2.5.8.11 (Build 37). This showed she did not have the CMT1A duplication or hereditary neuropathy with liability to pressure palsies (HNPP) deletion. Next generation sequencing of the coding region (+/- $5 \mathrm{bp}$ ) was performed using the Illumina TruSight One sequencing panel for the following genes: AARS (NM_001605.2); ARHGEF10 (NM_014629.2); ATL1 (NM_015915.4); CTDP1 (NM_004715.4); DNM2 (NM_001005361.2); DNMT1 (NM_001130823.1); DST (NM_015548.4);
DYNC1H1 (NM_001376.4); EGR2 (NM_000399.3); FAM134B (NM_001034850.2); FBLN5 (NM_006329.3); FGD4 (NM_139241.2); FIG4 (NM_014845.5); GAN (NM_0220 $\overline{4} 1.3$ ); GARS (NM_002047.2); GDAP1 (NM_018972.2); GJB1 (NM_000166.5); HOXD10 (NM_002148.3); HSPB1 (NM_001540.3); HSPB8 (NM_014365.2); IKBKAP (NM_003640.3); KARS (NM_001130089.1); KIF1A (NM_001244008.1); KIF1B (NM_015074.3); LITAF (NM_004862.3); LMNA (NM_170707.3); LRSAM1 (NM_-138361.5); MED25 (NM_030973.3); MFN2 (NM_014874.3); MPZ (NM_000530.6); MTMR14 (NM_001077525.2); MTMR2 (NM_016156.5); NDRG1 (NM_006096.3); NGF (NM_002506.2); NTRK1 (NM_002529.3); PMP22 (NM_000304.2); PRPS1 (NM_002764.3); PRX (NM_181882.2); RAB7A (NM_004637.5); REEP1 (NM_022912.2); SBF2 (NM_030962.3); SH3TC2 (NM_024577.3); SLC12A6 (NM_133647.1); SOX10 (NM_006941.3); SPTLC1 (NM_006415.2); SPTLC2 (NM_004863.3); TRPV4 (NM_021625.4); WNK1 (NM_001184985.1); YARS (NM_003680.3). 99.2\% of the target sequence within this panel was sequenced to a depth of 20 fold or more, with analytical sensitivity of $98.3 \%-100 \%(95 \%$ Confidence Intervals).

Sanger sequencing with fluorescence sequence analysis was performed in peripheral blood samples from both parents and a saliva sample from the proband's father. Next generation
Fig. 1 Clinical photographs showing muscle atrophy and foot deformities in the proband aged 5 years, and classical pes cavus with normal muscle bulk in her father aged 30 years

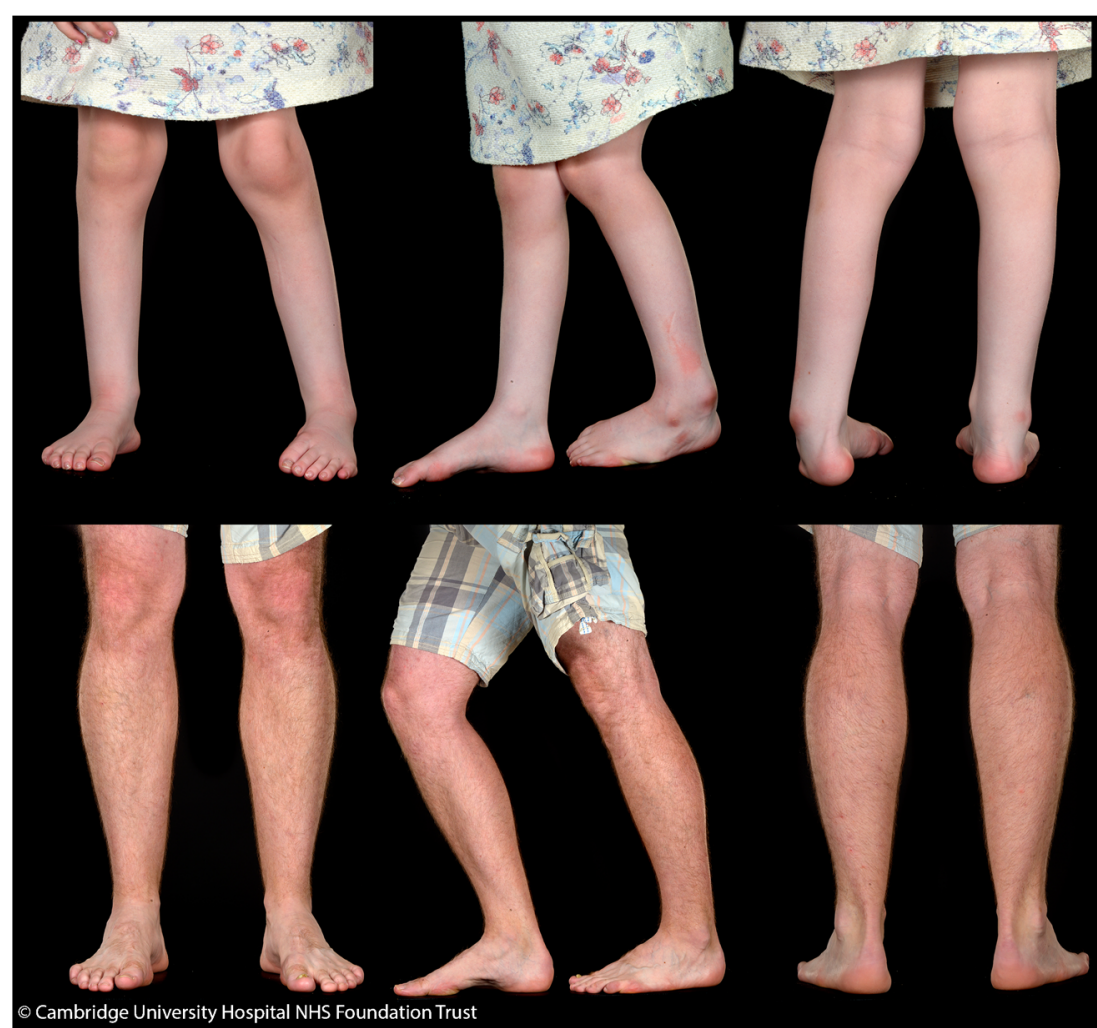


sequence analysis of the PCR product containing the pathogenic variant was subsequently performed in the father to quantify the level of mosaicism.

\section{Clinical Report}

A four-year old, first born girl of an unrelated Caucasian couple was referred with gait abnormalities and progressively worsening foot deformities. The pregnancy and birth history was normal. She crawled at 6 months and walked at 12 months but her gait remained unsteady with recurrent falls and trips, particularly in the mornings. Progressive in-turning of her left foot was noted from age two and a half years and she was referred for physiotherapy. Physiotherapy review at age $31 / 2$ years revealed that she was unable to run or walk long distances (necessitating wheelchair use) and could only get up off the floor with halfkneeling. Parents also gave a history of difficulty climbing stairs and recurrent leg pain. There were no concerns about her upper limb function or power and speech and language development was normal. There were no swallowing difficulties or salivary drooling. There was no history of neuro-regression or seizures and no concerns regarding hearing or vision.

Head circumference was $49.5 \mathrm{~cm}$ (50th centile). She was noted to be hypermobile with Beighton score $5 / 9$ and significant in-rolling of her left and right feet $(\mathrm{L}>>\mathrm{R})$. There was good antigravity power in her upper and lower limbs. Deep tendon reflexes were present in upper and lower limbs. Gower's manoeuvre was negative. She walked with dystonic posturing of both feet and could not jump high. There was no dysarthria and no dysmetria; cranial nerve examination was normal with no ophthalmoplegia or ptosis.

Blood tests showed normal CK, lactate and acylcarnitine. Nerve conduction studies at age $31 / 2$ showed absent sensory and motor responses in the legs (tibial, common peroneal and sural nerves tested). Electromyography revealed a reduced
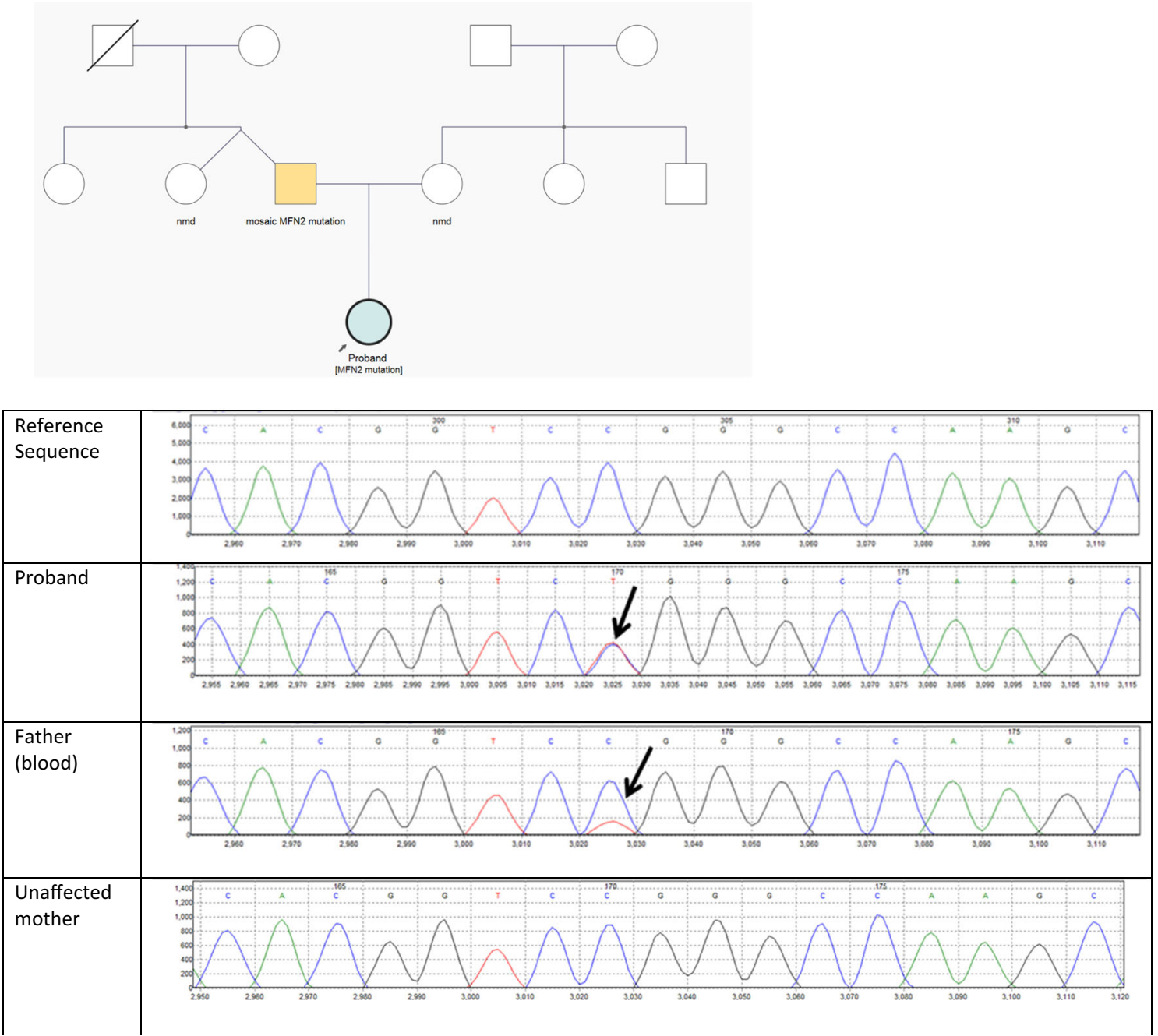

Fig. 2 Pedigree and screenshot of sequencing data from Mutation Surveyor, showing the reference sequence, proband, father (peripheral blood) and mother. The c.1090C > T, p.(Arg364Trp) heterozygous variant is seen in the proband, and at a level of approximately $20 \%$ in her father 
interference pattern with no spontaneous activity in the motor units tested (tibialis anterior), suggestive of a severe axonal neuronopathy However motor nerve conduction studies in upper limbs was normal $(58.8 \mathrm{~m} / \mathrm{s})$ which also raised the possibility of a spinal cord pathology but the MRI spine was normal. MRI of the brain and X-ray of the lower legs and hips were also undertaken and were normal.

The in-turning of her left foot developed rapidly to a quite marked equinovalgus deformity with marked forefoot metatarsal plantar flexion. This was treated with ankle foot orthoses and serial castings. Figure 1 shows clinical photographs of her lower legs aged 5 years.

Genetic testing was performed for a panel of genes associated with CMT. A previously reported pathogenic variant $[9$, 10] was detected in the $M F N 2$ gene c. $1090 \mathrm{C}>\mathrm{T}$, p.(Arg364Trp). This missense mutation affects a highly conserved amino acid and there is a moderate physicochemical difference between the arginine and tryptophan amino acids. Individuals with this mutation have been reported both with and without optic atrophy. No other variants were found. Subsequent ophthalmology review was normal and annual ophthalmology follow up was arranged.

There was no reported family history of CMT. Both parents were keen runners. On initial examination, high arched feet were noted in her 30-year old father (see clinical photographs in Fig. 1). Testing of parental blood samples by fluorescent sequence analysis detected the familial MFN2 mutation in her father at a low level of approximately $20 \%$ suggestive of mosaicism. Figure 2 shows the pedigree and Sanger sequencing data. The mutation was also detected in his saliva sample at a low level. Next generation sequence analysis was used to quantify the level of mosaicism and showed a level of $21 \%$ in blood and 24\% in saliva. This is shown in Fig. 3.

On review, the father had normal motor milestones and had been a sporty child. He had been a member of the armed forces and enjoyed running as a hobby. On examination, he had classical pes cavus with callus formation on the outer aspect of the balls of his feet. He had no demonstrable weakness, reflexes were preserved. Sensory examination revealed reduced pinprick to mid-foot bilaterally and reduced vibration sense to the ankles. Ophthalmology review was normal.

The parents were advised that there was a high recurrence risk (up to 50\%) in subsequent pregnancies. After discussion of the reproductive options, the parents were referred for preimplantation genetic diagnosis.

\section{Discussion}

Mutations in MFN2 are the commonest genetic cause for axonal CMT. The proband showed typical features for the early onset form of the condition [3, 4]. Two recent studies of patients with CMT2A have revealed two patients with presumed gonadal mosaicism. Two siblings included in a recent study of

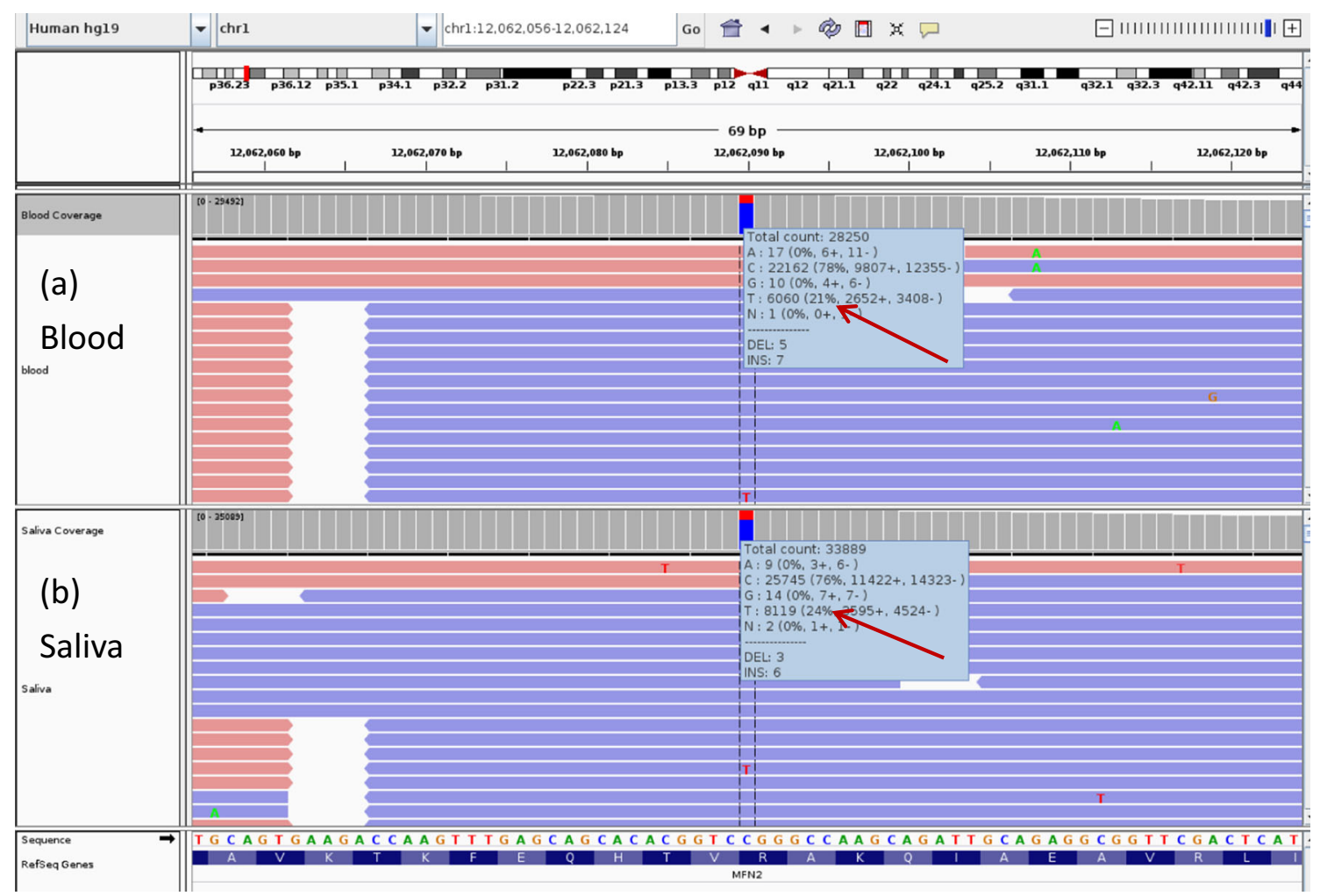

Fig. 3 Integrative Genomics Viewer (IGV) screenshot of the c.1090C > T MFN2 pathogenic variant. (a) blood DNA sample and (b) saliva DNA sample from patient's father. The level of mosaicism detected is $21 \%$ in the peripheral blood sample and $24 \%$ in the saliva sample 
Table 1 Summary of mutations, level of mosaicism, clinical features and neurophysiology findings in individuals with mosaic CMT

\begin{tabular}{|c|c|c|c|c|c|c|}
\hline Reference & Gene & Mutation & $\%$ mosaicism & $\begin{array}{l}\text { Reason for } \\
\text { ascertainment }\end{array}$ & Clinical Features & Neurophysiology \\
\hline This family & MFN2 & $\begin{array}{l}\text { c. } 1090 \mathrm{C}>\mathrm{T}, \\
\text { p.(Arg364Trp). }\end{array}$ & $\begin{array}{l}21 \% \text { (blood) } 24 \% \\
\quad \text { (saliva) }\end{array}$ & Affected child & $\begin{array}{l}\text { Bilateral pes cavus and reduced } \\
\text { sensation in feet aged } 30\end{array}$ & Not done \\
\hline Sorour & PMP22 & Duplication & $47.6 \%$ (blood) & Affected child & $\begin{array}{l}\text { Clawing of toes and clumsiness } \\
\text { since childhood, unsteadiness } \\
\text { of gait from } 40 \text { years, difficulty } \\
\text { with coordination in hands } \\
\text { from } 50 \text { years }\end{array}$ & $\begin{array}{l}\text { Normal median motor } \\
\text { conduction velocity } \\
\text { Significantly slow sural } \\
\text { sensory conduction velocity }\end{array}$ \\
\hline Liehr & PMP22 & Duplication & $\begin{array}{l}40-58 \% \text { (blood) } \\
66 \% \text { (hair root } \\
\text { cells) } 74 \% \\
\text { (nervous } \\
\text { tissues) } 51 \% \\
\text { (buccal } \\
\text { mucosa) }\end{array}$ & Clinical CMT & $\begin{array}{l}\text { Bilateral pes cavus, mild distal } \\
\text { weakness of arms and legs, } \\
\text { absent reflexes, sensory } \\
\text { disturbance distal to elbow and } \\
\text { knee at age } 25\end{array}$ & $\begin{array}{l}\text { Motor NCV from median, ulnar } \\
\text { and tibial nerves } 18-20 \mathrm{~m} / \mathrm{s} \\
\text { No sensory action potential } \\
\text { could be recorded from sural, } \\
\text { radial or median nerves }\end{array}$ \\
\hline Rautenstrauss & PMP22 & Duplication & $\begin{array}{l}60 \% \text { blood } 88 \% \\
\text { nerve tissue } \\
72 \% \text { muscle }\end{array}$ & Clinical CMT & $\begin{array}{l}\text { Signs and symptoms of a } \\
\text { demyelinating neuropathy } \\
\text { aged } 4\end{array}$ & \\
\hline Grehl & PMP22 & Duplication & $\begin{array}{l}49 \% \text { blood } 74 \% \\
\text { sural nerve }\end{array}$ & Clinical CMT & $\begin{array}{l}\text { Generalised weakness arms and } \\
\text { legs from age } 21 \text {, burning pains } \\
\text { in shoulders, hands and feet, } \\
\text { bilateral pes cavus, mild } \\
\text { distally pronounced weakness } \\
\text { in arms and legs, sensory } \\
\text { disturbance distal to elbow and } \\
\text { knee }\end{array}$ & $\begin{array}{l}\text { Motor NCV from median, ulnar } \\
\text { and tibial nerves } 18-20 \mathrm{~m} / \mathrm{s} \\
\text { No sensory action potential } \\
\text { could be recorded from sural, } \\
\text { radial or median nerves }\end{array}$ \\
\hline Taioli & PMP22 & $\begin{array}{l}\text { c. } 117 \mathrm{G}>\mathrm{C}, \\
\text { p.(Trp39Cys })\end{array}$ & $20 \%$ (blood) & $\begin{array}{l}2 \text { affected } \\
\text { children }\end{array}$ & $\begin{array}{l}\text { Subclinical age } 29 \text { Pes cavus, } \\
\text { decreased ankle jerk reflexes } \\
\text { and vibration sensation in legs }\end{array}$ & $\begin{array}{l}\text { Slight reduction in sural nerve } \\
\text { action potentials }\end{array}$ \\
\hline Borgulova & GJB1 & c.784_786delTA & $25 \%$ (blood) & $\begin{array}{l}\text { Affected } \\
\text { daughter }\end{array}$ & $\begin{array}{l}\text { Asymptomatic Abnormal } \\
\text { electrophysiology }\end{array}$ & $\begin{array}{l}\text { Motor NCV from median } \\
43.9 \mathrm{~m} / \mathrm{s} \text {, ulnar } 52.9 \text {, tibial } \\
\text { 33.3. }\end{array}$ \\
\hline Kochanski & GJB1 & p. Glu208Lys & Not stated & $\begin{array}{l}\text { Affected } \\
\text { grandson }\end{array}$ & $\begin{array}{l}\text { Mild clinical CMT Unable to } \\
\text { walk on heels from age } 11 \text {, } \\
\text { slowly progressive mild } \\
\text { disease }\end{array}$ & Not done \\
\hline Baker & GJB1 & $\begin{array}{l}\text { c. } 95 \mathrm{G}>\mathrm{A}, \\
\text { p.(Arg32Lys) }\end{array}$ & $\begin{array}{l}\text { Approx one third } \\
\text { (blood) }\end{array}$ & $\begin{array}{l}\text { Symptoms of } \\
\text { carpal } \\
\text { tunnel } \\
\text { syndrome }\end{array}$ & $\begin{array}{l}\text { Bilateral carpal tunnel syndrome } \\
\text { age } 39 \text { Absent ankle jerk } \\
\text { reflexes Mild stocking } \\
\text { distribution pin hypoaesthesia }\end{array}$ & $\begin{array}{l}\text { Ulnar, deep peroneal, tibial } \\
\text { motor NCS normal, absent } \\
\text { superficial peroneal SNAP, } \\
\text { low amplitude sural SNAP }\end{array}$ \\
\hline Fabrizi & $M P Z$ & $\begin{array}{l}\text { c.308G > A, } \\
\text { p.(Gly74Glu) }\end{array}$ & $\begin{array}{l}20 \% \text { (blood) } 30 \% \\
\text { (skin, buccal } \\
\text { epithelium, } \\
\text { hair) }\end{array}$ & $\begin{array}{l}2 \text { affected } \\
\text { children }\end{array}$ & Asymptomatic. Pes planus. & Normal \\
\hline
\end{tabular}

43 French patients with CMT2A were affected with early onset peripheral neuropathy and optic atrophy. A novel pathogenic missense variant (c.775C > T, p.(Arg259Cys) was detected in both siblings but not in their clinically unaffected parents [4]. A study of Czech hereditary motor and sensory neuropathy type II patients detected 8 pathogenic MFN2 mutations, including two sisters affected with axonal CMT neuropathy. A novel pathogenic missense variant c. $314 \mathrm{C}>\mathrm{G}$, p.(Thr105Arg) was detected in both sisters but not observed in their clinically unaffected parents [11]. To the best of our knowledge, somatic mosaicism has not been previously reported in CMT2A.
The proband's mosaic father showed minimal clinical features of CMT. There is considerable variability is seen in dominantly inherited CMT2A, with some patients having a later onset, milder form of the disease [3, 4]. However, his very mild features are most likely to be explained by the somatic mosaicism.

Mosaicism has been previously reported in other forms of CMT, with a very variable clinical phenotype including asymptomatic with normal neurophysiology studies [12], subclinical disease [13], mild clinical disease [14-16] and typical presentations of CMT1A with somatic mosaicism found on genetic testing [17-19]. The mutations, level of mosaicism, 
clinical features and neurophysiology findings from the literature are summarised Table 1.

Individuals with mild or subclinical CMT due to somatic mosaicism who have been ascertained through an affected child (or grandchild) have been described for CMT1A [16] , CMTX1 [13, 14], and CMT1E [15].

A family with CMT1B has been described with two severely affected sisters. A mutation in $M P Z$ was found in both affected sisters and in mosaic form in their mother ( $20 \%$ in blood, $30 \%$ in skin, buccal epithelium and hair) who was clinically unaffected with normal neurophysiology studies [12].

Three cases of somatic mosaicism for the PMP22 duplication with clinical findings typical for CMT1 have been described [16-18]. The level of mosaicism was fairly high in these individuals (range 40-88\%). A man with mosaic CMTX1 has also been described who presented with symptoms of bilateral carpel tunnel syndrome [20].

The level of mosaicism detected in blood and saliva in the proband's father was quite low (at around 20\%). The similar levels of mosaicism found in blood and saliva suggest that the mosaic mutation happened early in embryogenesis since it is found in both ectodermal and mesodermal tissue. However, a nerve biopsy was not undertaken, so it is possible that the level of mosaicism in the neurons and/or Schwann cells may be higher. This could explain why he has foot deformities despite the low level of mosaicism. It has been recognised that it is difficult to predict disease severity in mosaic disorders [8].

The family which we have described highlights the need for parental testing in order to give reliable information about recurrence risk. The diagnosis of mosaic CMT2A would have been missed on the basis of family history without molecular testing. As the father has proven somatic mosaicism and an affected child, gonadal mosaicism is assumed. Estimating the recurrence risk in this situation is challenging. The family were counselled for a high risk of 'up to 50\%' risk.

Next generation sequencing is likely to detect lower levels of mosaicism. It has been suggested that deep sequencing of blood for pathogenic apparently de novo mutations seen in children could be used to pick up low level mosaicism [21]. Families with no evidence of mosaicism would have a $<1 \%$ recurrence risk, but those with low level mosaicism would have a significantly higher risk.

Next generation sequencing was used to quantify the level of mosaicism in the father's blood and saliva samples with greater accuracy than estimating the level from Sanger sequencing. However, we do not yet have a way of estimating recurrence risks based on the observed level of mosaicism. Further studies are needed to determine the most effective ways of estimating the recurrence risk and communicating the information to families.

Acknowledgements We would like to thank the family for their participation and Terence Elsey for his contribution to the sequence analysis and Dr. Julian Ray for performing the nerve conduction studies and electromyography. KS would like to thank the National Institute of Health Research for funding her Academic Clinical Fellowship job. This work was done as part of routine NHS care and did not require funding. We do not have any competing interests.

Open Access This article is distributed under the terms of the Creative Commons Attribution 4.0 International License (http:// creativecommons.org/licenses/by/4.0/), which permits unrestricted use, distribution, and reproduction in any medium, provided you give appropriate credit to the original author(s) and the source, provide a link to the Creative Commons license, and indicate if changes were made.

\section{References}

1. Skre H (1974) Genetic and clinical aspects of Charcot-MarieTooth's disease. Clin Genet 6(2):98-118

2. Rossor AM, Polke JM, Houlden H, Reilly MM (2013) Clinical implications of genetic advances in Charcot-Marie-tooth disease. Nat Rev Neurol 9(10):562-571

3. Verhoeven K, Claeys KG, Züchner S, Schröder JM, Weis J, Ceuterick C et al (2006) MFN2 mutation distribution and genotype/phenotype correlation in Charcot-Marie-tooth type 2 . Brain J Neurol 129(Pt 8):2093-2102

4. Bombelli F, Stojkovic T, Dubourg O, Echaniz-Laguna A, Tardieu S, Larcher K et al (2014) Charcot-Marie-tooth disease type 2A: from typical to rare phenotypic and genotypic features. JAMA Neurol 71(8):1036-1042

5. Nicholson GA, Magdelaine C, Zhu D, Grew S, Ryan MM, Sturtz F et al (2008) Severe early-onset axonal neuropathy with homozygous and compound heterozygous MFN2 mutations. Neurology 70(19):1678-1681

6. Polke JM, Laurá M, Pareyson D, Taroni F, Milani M, Bergamin G et al (2011) Recessive axonal Charcot-Marie-tooth disease due to compound heterozygous mitofusin 2 mutations. Neurology 77(2): 168-173

7. Campbell IM, Shaw CA, Stankiewicz P, Lupski JR (2015) Somatic mosaicism: implications for disease and transmission genetics. Trends Genet TIG 31(7):382-392

8. Biesecker LG, Spinner NBA (2013) Genomic view of mosaicism and human disease. Nat Rev Genet 14(5):307-320

9. Züchner S, De Jonghe P, Jordanova A, Claeys KG, Guergueltcheva $\mathrm{V}$, Cherninkova $\mathrm{S}$ et al (2006) Axonal neuropathy with optic atrophy is caused by mutations in mitofusin 2. Ann Neurol 59(2):276281

10. Gowrisankaran S, Anastasakis A, Fishman GA, Alexander KR (2011) Structural and functional measures of inner retinal integrity following visual acuity improvement in a patient with hereditary motor and sensory neuropathy type VI. Ophthalmic Genet 32(3): 188-192

11. Brožková DŠ, Posádka J, Laššuthová P, Mazanec R, Haberlová J, Sišková D et al (2013) Spectrum and frequencies of mutations in the MFN2 gene and its phenotypical expression in Czech hereditary motor and sensory neuropathy type II patients. Mol Med Rep 8(6): 1779-1784

12. Fabrizi GM, Ferrarini M, Cavallaro T, Jarre L, Polo A, Rizzuto NA (2001) Somatic and germline mosaic mutation in MPZ/P $(0)$ mimics recessive inheritance of CMT1B. Neurology 57(1):101-105

13. Borgulová I, Mazanec R, Sakmaryová I, Havlová M, Safka Brožková D, Seeman P (2013) Mosaicism for GJB1 mutation causes milder Charcot-Marie-tooth X1 phenotype in a heterozygous man than in a manifesting heterozygous woman. Neurogenetics 14(3-4):189-195 
14. Kochanski A, Nowakowski A, Kawulak M, Kabzińska D, Hausmanowa-Petrusewicz I (2004) Somatic mosaicism in Charcot-Marie-tooth type X disease. Neurology 62(2):336-337

15. Taioli F, Bertolasi L, Ajena D, Ferrarini M, Cabrini I, Crestanello A et al (2012) Parental mosaicism of a novel PMP22 mutation with a minimal neuropathic phenotype. J Peripher Nerv Syst JPNS 17(4): 414-417

16. Sorour E, Thompson P, MacMillan J, Upadhyaya M (1995) Inheritance of CMT1A duplication from a mosaic father. J Med Genet 32(6):483-485

17. Liehr T, Rautenstrauss B, Grehl H, Bathke KD, Ekici A, Rauch A et al (1996) Mosaicism for the Charcot-Marie-tooth disease type 1A duplication suggests somatic reversion. Hum Genet 98(1):22-28
18. Rautenstrauss B, Liehr T, Fuchs C, Bevot A, Bornemann A, Postler E et al (1998) Mosaicism for Charcot-Marie-tooth disease type 1A: onset in childhood suggests somatic reversion in early developmental stages. Int J Mol Med 1(2):333-337

19. Grehl H, Rautenstrauss B, Liehr T, Bickel A, Ekici A, Bathke K et al (1997) Clinical and morphological phenotype of HMSN 1A mosaicism. Neuromuscul Disord NMD 7(1):27-31

20. Baker SK, Reith CC, Ainsworth PJ (2008) Novel 95G > A (R32K) somatic mosaic connexin 32 mutation. Muscle Nerve 38(5):15101514

21. Rahbari R, Wuster A, Lindsay SJ, Hardwick RJ, Alexandrov LB, Al Turki $S$ et al (2016) Timing, rates and spectra of human germline mutation. Nat Genet 48(2):126-133 